\title{
An Analysis of X-Band Calibrated Sea Clutter and Small Boat Reflectivity at Medium-to-Low Grazing Angles
}

\author{
P. L. Herselman, ${ }^{1}$ C. J. Baker, ${ }^{2}$ and H. J. de Wind ${ }^{1}$ \\ ${ }^{1}$ CSIR Defence, Peace, Safety and Security, P.O. Box 395, Pretoria 0001, South Africa \\ ${ }^{2}$ Department of Electronic and Electrical Engineering, University College London, Torrington Place, London WC1E 7JE, UK
}

Correspondence should be addressed to P. L. Herselman, pherselman@csir.co.za

Received 15 February 2008; Accepted 4 June 2008

Recommended by Simon Watts

The coherent temporal characteristics of medium-to-low grazing angle sea clutter and small boat reflectivity are considered for different radar waveforms under a range of environmental conditions and geometrical configurations. Accurate empirical modelling of sea clutter enables the inference of the local sea conditions from radar returns, pertinent for port safety and navigation. Understanding the dynamics and associated reflectivity of small boats, in addition to empirical sea clutter models, allows the development of advanced detection and tracking algorithms, which will improve the performance of surveillance and marine navigation radar against small boats. Work presented is based on the empirical analysis of data recorded with two calibrated, coherent, pulsed radar systems at X-band frequencies. Specifically, target echoes from small boats are included in the datasets and subsequent analysis.

Copyright ( 2008 P. L. Herselman et al. This is an open access article distributed under the Creative Commons Attribution License, which permits unrestricted use, distribution, and reproduction in any medium, provided the original work is properly cited.

\section{INTRODUCTION}

There is a growing need for accurate, real-time instrumentation of the sea surface for safe navigation of vessels in and around harbours and shipping lanes. A commercial product, wave and surface current monitoring system (WaMoS) [1], can be connected to a conventional X-band marine radar. WaMoS II processes the unfiltered sea clutter to estimate the wave and surface current parameters in near real-time. According to the manufacturers the instrumented range is $0.1-3 \mathrm{~km}$. At $\mathrm{X}$-band operating frequencies, the main scattering mechanism is that of Bragg scattering, associated with the resonant capillary waves [2]. Capillary waves, in turn, are generated by the local near-surface wind and do not propagate beyond the breeze area. Only in a fully developed sea can the wave height be directly related to the present wind speed and can the significant wave height $H_{s}$ be accurately inferred from the average sea clutter reflectivity [3]. In transient sea conditions, the best fit for the Georgia Institute of Technology (GIT) mean sea clutter reflectivity model [4] is found if the sea state is related to the local mean wind speed rather than $H_{s}[5,6]$. It can therefore be deduced that it is possible to also infer local wind conditions from X-band sea clutter. This article investigates the temporal characteristics of coherent sea clutter, with specific interest in the Doppler characteristics of sea clutter and the relationship thereof to the local wind and wave conditions (e.g., average wind speed, wind direction, and wind gusts).

The significant increase in sea clutter reflectivity in rough seas with strong winds, together with relatively small radar cross section (RCS) of small boats (e.g., yachts, ski boats, and rigid inflatable boats (RIBs)), has often been blamed for disasters at sea where large ships collided with these small boats [7]. In certain cases, the marine radar could not discern the boat signature from the clutter, while in other cases there were too many false tracks established leading to the subsequent disabling of the automatic tracker. For safe navigation it is pertinent that the detection capabilities of marine radar in adverse conditions are improved. With the introduction of cheaper, solid-sate, coherent marine radar [8] a whole new class of coherent detection algorithms has become applicable to marine navigation radar, for example, [9-11]. Theoretical and first-order empirical analysis suggest subclutter visibility [11]. Little work has been presented on the performance of this class of detectors (often referred 
to as asymptotically optimal) on measured data of small boats [12]. No reference is made to the performance as a function of the type of manoeuvring of the boat and the influence of the boat on the surrounding sea surface. This article investigates the performance of the adaptive linear quadratic (ALQ) detector [11] under different boat manoeuvres for different types of RIBs, including the $4.2 \mathrm{~m}$ pencilduck type that is often used for watersport racing. This boat has a very small RCS, but since it has a racing speed of up to $40 \mathrm{kts}$ the local disturbance of the sea surface often exceeds the boat RCS by up to $10 \mathrm{~dB}$. With improved subclutter visibility, the problem arises that first detections are declared not only for small boats, but also for large birds such as seagulls, with a typical RCS of $0.01-0.1 \mathrm{~m}^{2}[3]$, and angels (flocks of birds flying together). Effective algorithms to discard tracks established on birds have to be developed [13].

Typical scanning surveillance systems (including maritime radar) have to declare a detection using only a limited number of pulses. Due to the long decorrelation time of sea clutter [14] and the more often than not spiky amplitude statistics [15], detection is quite difficult due to the short dwell time. Persistent, ubiquitous surveillance has become a top priority internationally. Typical entities of interest range from small recreational watercraft to large tanker ships. One of the characteristics of such systems, for instance, AwareNet [16], is the ability to employ long dwell times at specific areas of interest through the utilization of multiple, electronically steered receiver channels. Improved discernibility of small boats with long dwell times is therefore investigated in this article.

Two sea clutter and boat reflectivity measurement trials were conducted in 2006 and 2007 on the south western coast of South Africa. The aim of these trials was firstly to record datasets of sea clutter returns at different frequencies, range resolutions, grazing angles, look angles, and environmental conditions to validate current sea clutter models. Secondly, the aim was to record boat reflectivity datasets for a number of small boats to investigate its detectability with open literature detectors that will hopefully lead to the development of improved detection algorithms for radar systems employing adaptive dwell times.

The layout of the article is as follows. Section 2 presents an overview of the two measurement trials. The results presented in this article were obtained from the analysis of the data recorded during these trials. A description is given of the different radar systems, the experimental setup, as well as the system and data integrity verification procedures. Section 3 investigates a subset of the sea clutter measurements, focusing on the amplitude statistics and temporal characteristics for fixed frequency and frequency agile waveforms. The RCS and temporal fluctuation of a variety of small boats are investigated in Section 4 for different manoeuvres. Of particular interest is the effect of the boat manoeuvring on the local sea surface and its subsequent reflectivity. Section 5 presents an analysis of the detectability of these small boats, seagulls, as well as angels.

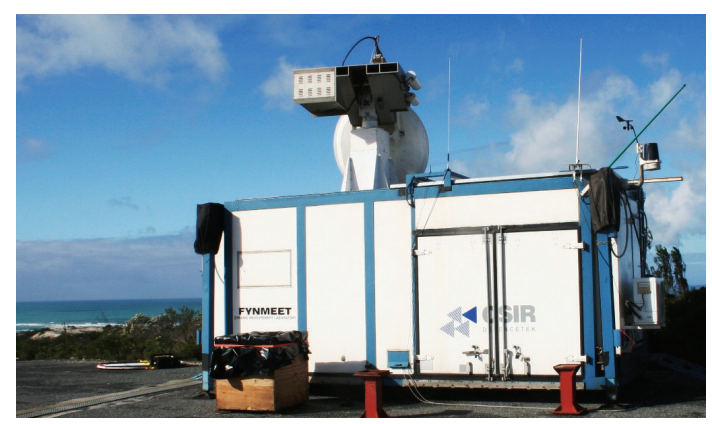

Figure 1: Fynmeet deployed at OTB.

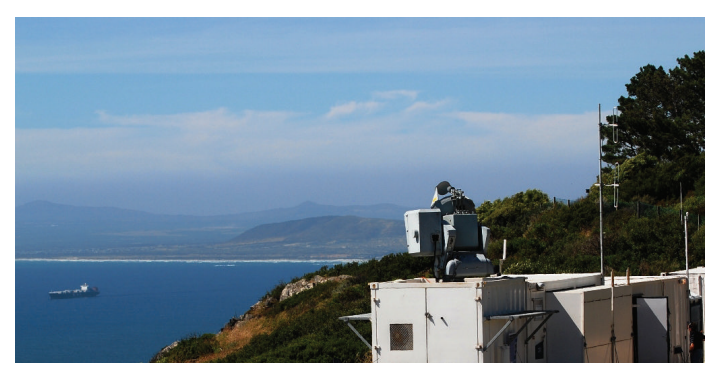

Figure 2: Radar deployed on Signal Hill with open view of sea.

\section{OVERVIEW OF MEASUREMENT TRIALS}

The first measurement trial was conducted with the Fynmeet dynamic RCS measurement facility (Figure 1) at the Overberg Test Range (OTB). The site provided azimuth coverage of $135^{\circ}$ predominantly up-swell with well-developed waves and with a significant variation in wind direction. Sea clutter at grazing angles $0.3-3^{\circ}$ were recorded. The second measurement trial was conducted with an experimental, monopulse, X-band radar (Figure 5) deployed on top of Signal Hill in Cape Town. This site provided azimuth coverage of $140^{\circ}$ from up- to cross-swell, but with only two predominant wind directions for the duration of the trial. The sea was more representative of open sea conditions. Sea clutter and littoral clutter at grazing angles $0.3-10^{\circ}$ were recorded. The experimental radar uses pulse compression to increase the system gain and subsequently yields extended range capabilities compared to Fynmeet.

\subsection{Overberg test range 2006 trial}

\subsubsection{Radar and experimental set-up}

The radar was deployed at OTB at location $34^{\circ} 36^{\prime} 56.52^{\prime \prime} \mathrm{S}, 20^{\circ} 17^{\prime} 17.46^{\prime \prime} \mathrm{E}, 67 \mathrm{~m}$ above mean sea level (AMSL). The shortest distance to the coastline was $1.2 \mathrm{~km}$ due south. A plan overview of the deployment site is depicted in Figure 2. The important specifications of Fynmeet are listed in Table 1.

Local wind speed and direction (Figure 4(a)) were logged with two weather stations separated by $1 \mathrm{~km}$. The local wave direction $\phi_{\text {wave }}$, significant wave height $H_{s}$, maximum wave height $H_{\max }$ and wave period $T_{\text {wave }}$ (Figure $4(\mathrm{~b})$ ) were logged 


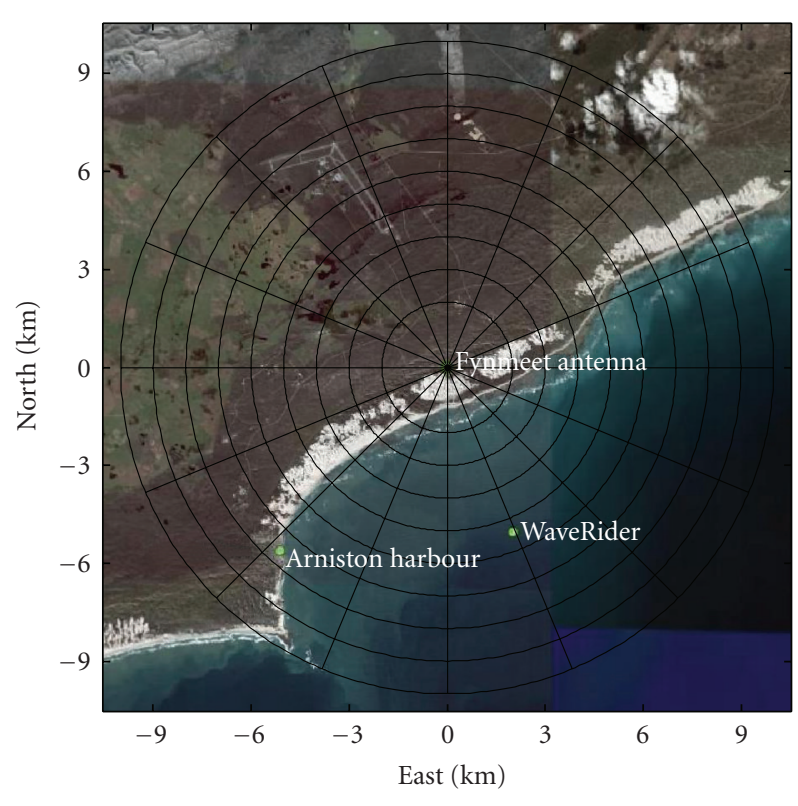

FIgURe 3: Plan overview of Fynmeet deployment site.

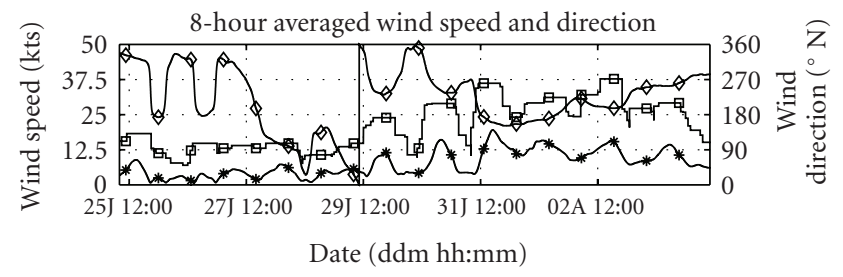

* Average

- Maximum

$\diamond$ Direction

(a)

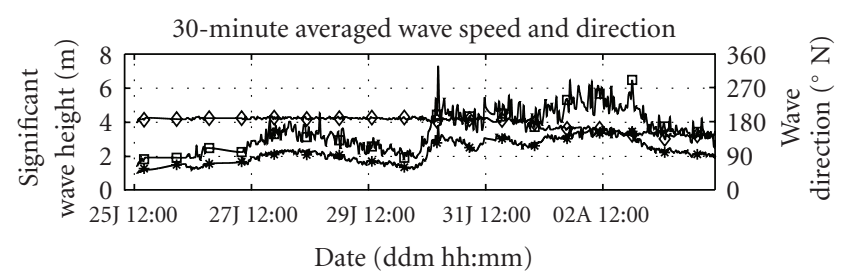

* Average

- Maximum

$\diamond$ Direction

(b)

FIgURE 4: Environmental conditions during OTB trial: (a) wind, and (b) wave.

with a directional recording wave buoy. The local wave structure is influenced greatly by significant weather patterns from the south west and further perturbed by the diffraction patterns due to the cape, southwest of the deployment site which is located in a small bay area with a sea bed depth varying between $10-30 \mathrm{~m}$ at ranges of $3-10 \mathrm{~km}$. The ground truth tracks of the boats were estimated using a differential processing global positioning system (GPS) receiver.
TABLE 1: Fynmeet system and performance specifications.

\begin{tabular}{|c|c|c|}
\hline \multirow{4}{*}{ Transmitter } & Frequency range & $6.5-17.5 \mathrm{GHz}$ \\
\hline & Peak power & $2 \mathrm{~kW}$ \\
\hline & PRF range & $0-30 \mathrm{kHz}$ \\
\hline & Waveforms & $\begin{array}{l}100 \text { and } 300 \mathrm{~ns} \text { pulsed } \\
\text { Continuous Wave }(\mathrm{CW}) \text {, } \\
\text { fixed/pulse-to-pulse frequency } \\
\text { agile }(500 \mathrm{MHz})\end{array}$ \\
\hline \multirow{4}{*}{ Antenna } & Type & Dual offset reflector \\
\hline & Gain & $\geq 30 \mathrm{~dB}$ \\
\hline & Beam width & $\leq 2^{\circ}(3 \mathrm{~dB}$ beam width $)$ \\
\hline & Side lobes & $\leq-25 \mathrm{~dB}$ \\
\hline \multirow{5}{*}{ Receiver } & Dynamic range & $\begin{array}{l}60 \mathrm{~dB} \text { (instantaneous)/120 dB } \\
\text { (total) }\end{array}$ \\
\hline & Capture range & $200 \mathrm{~m}-15 \mathrm{~km}$ \\
\hline & Range gates & $1-64 ; \Delta R=15 \mathrm{~m}$ or $45 \mathrm{~m}$ \\
\hline & Sampler type & $\begin{array}{l}\text { I/Q intermediate frequency } \\
\text { sampler }\end{array}$ \\
\hline & Image rejection & $\leq-41 \mathrm{dBc}$ \\
\hline
\end{tabular}

\subsubsection{System and data integrity verification}

For absolute RCS calibration the response from a sphere suspended below a helicopter, tracked in range with a typical $\alpha-\beta$ tracker and in angle with a video centroid tracker, was measured and the calibration coefficient was calculated as

$$
C_{\mathrm{cal}}=20 \log _{10}\left(\frac{1}{N} \sum_{n=1}^{N}\left|\sum_{m=M(n)-1}^{M(n)+1} x(n, m)\right| \frac{A R^{4}}{\sigma_{\mathrm{cs}}}\right),
$$

where $N$ is the number of pulses transmitted, $M(n)$ the range gate with maximum return for the $n$th pulse, $A$ the receiver attenuation, and $\sigma_{\mathrm{cs}}$ the sphere RCS. A standard deviation of $1 \mathrm{~dB}$ was achieved. Daily stability verification measurements were done with a corner reflector, exhibiting variations in the order of about $1 \mathrm{~dB}$ across the measurement period.

Linearity of the quadrature receiver channels were ascertained by the analysis of calibrated noise source, receiver noise, and blue sky measurements taken throughout the trial. This analysis included the estimation of channel skewness, kurtosis as well as the 2nd to 4th normalized intensity moments, $I_{2}-I_{4}$. The amplitude and phase imbalance of the quadrature channels were estimated as $0.03 \mathrm{~dB}$ and $1^{\circ}$ resulting in a negative Doppler image of $\leq-41 \mathrm{dBc}$. Additionally, there were also harmonically related spurious responses at a level of $\leq-50 \mathrm{dBc}$. A $5 \mathrm{MHz}$ leak-through signal was identified and removed from the data. The signal phase was nondeterministic and therefore the amplitude and phase were estimated from the dataset itself. Sea clutter with a strong steady state component biases this estimate and the best results were obtained by using a censored mean level technique in the estimation process. The percentage of the dataset censored was chosen such that the resultant estimate yielded the lowest variance. Applying the discrete fourier transform (DFT) to the corrected data, a $0 \mathrm{~Hz}$ frequency bin with a comparable power density to adjacent frequency 


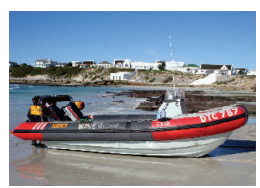

(a)

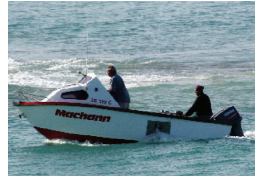

(b)

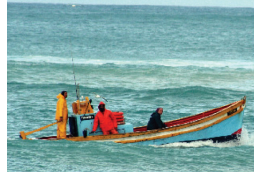

(c)
Figure 5: Boats deployed during OTB trial: (a) $5.7 \mathrm{~m}$ RIB, (b) ski boat, and (c) chokka fishing vessel.

bins was obtained without suppressing the steady state clutter response.

\subsubsection{Trial summary}

Sea clutter datasets were recorded over a period of 11 days, with 112 fixed frequency and 38 stepped frequency datasets centred at four transmit (Tx) frequencies over an azimuth angle range from $90^{\circ} \mathrm{N}$ to $225^{\circ} \mathrm{N}$ and a grazing angle range $0.3-3^{\circ}$. The local weather pattern may be described as roughly following a 6-day cycle [17] as cold front systems pass by from the west to the east. Over the trial period, the average wind speed ranged between 1-20 kts, with a maximum gust of $40 \mathrm{kts}$. Wind direction spanned $360^{\circ}$, but the high wind speeds were mainly from the south west. $H_{s}$ varied between $1-3.8 \mathrm{~m}$, with a maximum recorded wave height of $7.31 \mathrm{~m}$. The wave direction was roughly $180^{\circ} \mathrm{N}$, and slowly changed direction toward the end of the trial to $135^{\circ} \mathrm{N}$.

Even with a low wind speed of $1 \mathrm{kt}$, the significant wave height was $\geq 1 \mathrm{~m}$. This is due to the strong incoming south westerly swell combined with the diffraction patterns of the close-by cape and the reduction in sea depth. The illuminated sea area can therefore not be defined as a fully developed sea [3] and the standard tables relating wind speed and wave height to sea state do not apply. In terms of the average wind speed, sea states 1 to a low 5 were observed. In terms of the wave height, sea states from a high 2 to a high 5 were observed.

A $5.7 \mathrm{~m} \mathrm{RIB}$, a glass fibre ski boat and a wooden chokka fishing vessel (Figure 4) were deployed on 4 days with conditions ranging from calm to rough seas. The boats sailed a number of manoeuvres at different ranges and azimuth angles. A total of 55 fixed frequency and 43 stepped frequency datasets were recorded centred at four Tx frequencies.

The recorded datasets have been made available to the international research community. For information on the available datasets and how to access these datasets, refer to http://www.csir.co.za/small_boat_detection/.

\subsection{Signal hill 2007 trial}

\subsubsection{Radar and experimental set-up}

The experimental, X-band, monopulse radar was deployed on Signal Hill at location $33^{\circ} 55^{\prime} 15.62^{\prime \prime} \mathrm{S}, 18^{\circ} 23^{\prime} 53.76^{\prime \prime} \mathrm{E}$, $308 \mathrm{~m}$ AMSL, as indicated on the plan view in Figure 6. The shortest distance to the coast line was $1250 \mathrm{~m}$ at a bearing of $288^{\circ} \mathrm{N}$. The site provided $140^{\circ}$ azimuth coverage from $240^{\circ} \mathrm{N}$

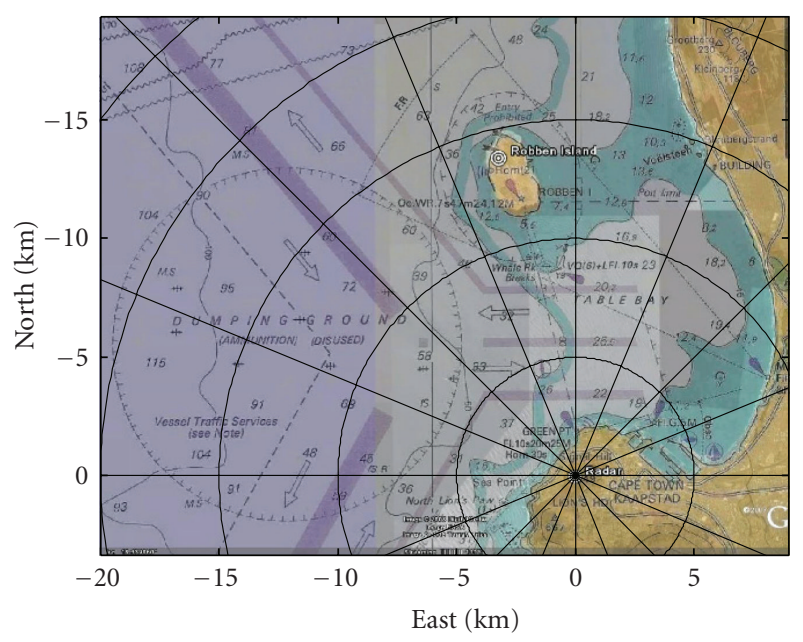

Figure 6: Plan overview of radar deployment site.

to $20^{\circ} \mathrm{N}$, of which a large sector spanned open sea whilst the remainder looked towards the West Coast coastline from the direction of the open sea. The radar had an open view of Robben Island at a distance of $11 \mathrm{~km}$. Grazing angles ranging from $10^{\circ}$ at the coastline to $0.3^{\circ}$ at the radar instrumented range of $60 \mathrm{~km}$ were obtained.

Local wind conditions (Figure 8(a)) were measured at the radar, Robben Island, Cape Town Harbour as well as Slangkop (south-southwest of the radar). The local wave conditions (Figure 8(b)) were measured with a seabed-based wave sensor at Camp's Bay and a directional wave buoy at Cape Point whilst numerically modelled at eight other locations in Table Bay and around Robben Island. The tracks of the instrumented boats (Figure 8) were estimated using a differential-processing GPS receiver.

\subsubsection{System and data integrity verification}

Due to the similarity of the two radar systems, similar system and data integrity verification process were followed as for the Fynmeet radar described in Section 2.1.2. The experimental radar employs matched filter pulse compression, where pulse compression codes $c_{\mathrm{pc}}$ are designed to yield a specific pulse compression gain, sidelobe levels and blind range. In the calibration procedure the height and range of the helicopter carrying the calibration sphere over the sea were restricted. The above-mentioned restrictions result in not all codes being calibrated. It is possible however, to estimate $C_{\text {cal }}$ for the uncalibrated codes from the calibrated codes by adding the relative pulse compression gain for the uncalibrated code

$$
G_{\mathrm{pc}}=\frac{\sum_{n=1}^{N} \mid\left. c_{\mathrm{pc}}(\text { uncal }, n)\right|^{2}}{\sum_{k=1}^{K}\left|c_{\mathrm{pc}}(\mathrm{cal}, k)\right|^{2}},
$$

where $N$ is the uncalibrated and $K$ the calibrated code lengths. Equation (2) is valid for a matched filter with unit noise gain. Similarly, the Doppler processing gain 


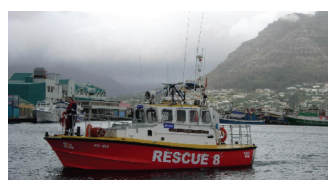

(a)

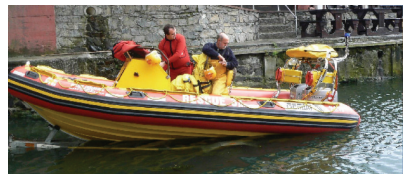

(b)

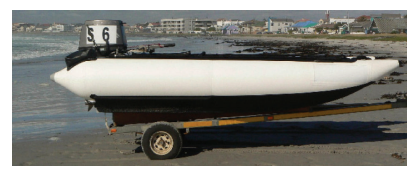

(c)

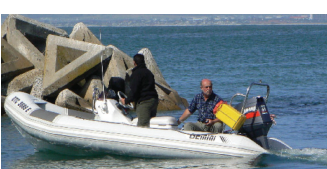

(d)

FIgURE 7: Boats deployed during Signal Hill trial: (a) Nadine Gordimer, (b) Rotary Endeavour, (c) pencilduck, and (d) SANParks RIB.

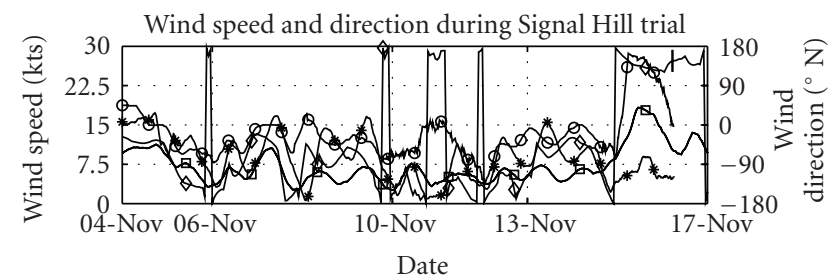

* Speed-local o Direction-local

Speed-Robben island $\diamond$ Direction-Robben island

(a)

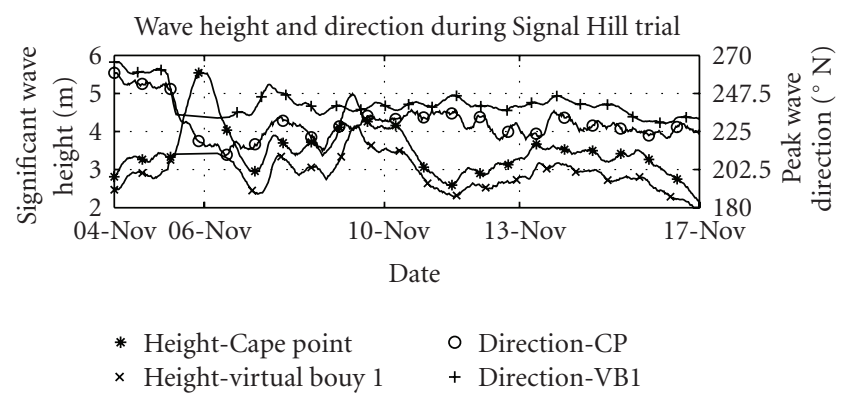

(b)

FIgURE 8: Environmental conditions during Signal Hill trial: (a) wind, and (b) wave.

can be estimated for the uncalibrated Doppler processing coefficients $c_{\mathrm{dp}}$,

$$
G_{\mathrm{dp}}=\frac{\left.\left[\sum_{l=1}^{L} c_{\mathrm{dp}}(\mathrm{cal}, l)\right)^{2}\right]\left[\sum_{m=1}^{M} c_{\mathrm{dp}}(\text { uncal, } m)\right]^{2}}{\left[\sum_{l=1}^{L} c_{\mathrm{dp}}(\mathrm{cal}, l)\right]^{2}\left[\sum_{m=1}^{M} c_{\mathrm{dp}}(\text { uncal }, m)^{2}\right]},
$$

where $M$ is the uncalibrated and $L$ the calibrated Doppler processing coefficient lengths. For the experimental radar, the image rejection and spurious response is sufficiently below the noise floor. Pulse compression codes utilized during the measurement trial yielded range sidelobe levels in the order of $-35 \mathrm{~dB}$.

\subsubsection{Trial summary}

Sea clutter datasets were recorded on eight different days over a period of thirteen days. The predominant wind direction was northwestern, but with southeastern intervals. The average wind speed varied between $0 \mathrm{kts}$ and $40 \mathrm{kts}$, with a maximum gust of $60 \mathrm{kts}$. The significant wave height ranged in 1-4.5 $\mathrm{m}$, whilst the swell direction varied between $230^{\circ} \mathrm{N}$ and $270^{\circ} \mathrm{N}$.
Datasets of the instrumented boats depicted in Figure 8 were recorded on five different days.

The Nadine Gordimer is a $10 \mathrm{~m}$ Class A deep sea rescue vessel with two MTU 1000 turbo diesel inboard motors and a range of communication antennas. The Rotary Endeavour is a Class $35.5 \mathrm{~m}$ RIB with two $60 \mathrm{hp}$ Yamaha outboard motors and a single VHF antenna. The South African National Parks (SANParks) RIB is a $4.8 \mathrm{~m}$ RIB with a $60 \mathrm{hp}$ Yamaha outboard motor. The $4.2 \mathrm{~m}$ pencilduck has a single $50 \mathrm{hp}$ outboard motor with no antennas. In addition, datasets were recorded for a large variety of noncooperative boats of opportunity. Recordings were made using a range of fixed frequency and stepped frequency waveforms.

\section{SEA CLUTTER ANALYSIS}

Various statistical properties are evaluated in this section for seven sea clutter datasets recorded during the OTB 2006 measurement trial. These datasets represent low and high sea states at grazing angles $1^{\circ}$ and $0.5^{\circ}$ for a single Tx frequency and pulse widths of 100 nanoseconds and 300 nanoseconds. The range-time intensity plot for the high sea state, $1^{\circ}, 100$ nanoseconds dataset CFC16-001 is presented in Figure 9.

The strong underlying modulation caused by the well developed waves is clearly visible for this up-swell configuration dataset. For cross-swell configurations and further ranges coupling between the waves and the underlying modulation becomes less pronounced as multiple waves are contained within a resolution cell, which is defined by the azimuth beamwidth and radar range resolution at low grazing angles. The underlying modulation also becomes less pronounced in weaker swell conditions.

\subsection{Mean reflectivity and amplitude statistics}

The mean reflectivity $\sigma_{0}$ and clutter-to-noise ratio (CNR) for the different OTB 2006 datasets are tabulated in Table 2 and compared to the GIT and the hybrid (HYB) models [4]. In both models the sea state $S$ was derived from the mean wind speed $v_{\text {wind }}$ using the empirical relation

$$
v_{\text {wind }}=3.16 S^{0.8} \text {. }
$$

From Table 2 it can be concluded that there is good agreement between empirical $\hat{\sigma}_{0}$ and the HYB model, with values generally between that of the HYB and the GIT. The GIT typically underestimates $\sigma_{0}$ at low grazing angles for low sea states by a significant margin, as discussed in detail in [4]. Of particular interest is the good fit found by matching 
TABLe 2: Empirical reflectivity $\left[\mathrm{dBm}^{2} / \mathrm{m}^{2}\right]$ and CNR $[\mathrm{dB}]$.

\begin{tabular}{|c|c|c|c|c|c|c|}
\hline Sea state & Low & Low & Low & Low & High & High \\
\hline Grazing angle & $1^{\circ}$ & $0.5^{\circ}$ & $1^{\circ}$ & $0.5^{\circ}$ & $1^{\circ}$ & $0.5^{\circ}$ \\
\hline Resolution [m] & 15 & 15 & 45 & 45 & 15 & 15 \\
\hline $\mathrm{CNR}[\mathrm{dB}]$ & 11 & -3 & 17 & 5 & 21 & 7 \\
\hline Reflectivity $\left[\mathrm{dBm}^{2} / \mathrm{m}^{2}\right]$ & -48 & -51 & -51 & -52 & -39 & -41 \\
\hline GIT model $\left[\mathrm{dBm}^{2} / \mathrm{m}^{2}\right]$ & -101 & -115 & -101 & -115 & -35 & -39 \\
\hline HYB model $\left[\mathrm{dBm}^{2} / \mathrm{m}^{2}\right]$ & -47 & -53 & -47 & -53 & -36 & -39 \\
\hline
\end{tabular}

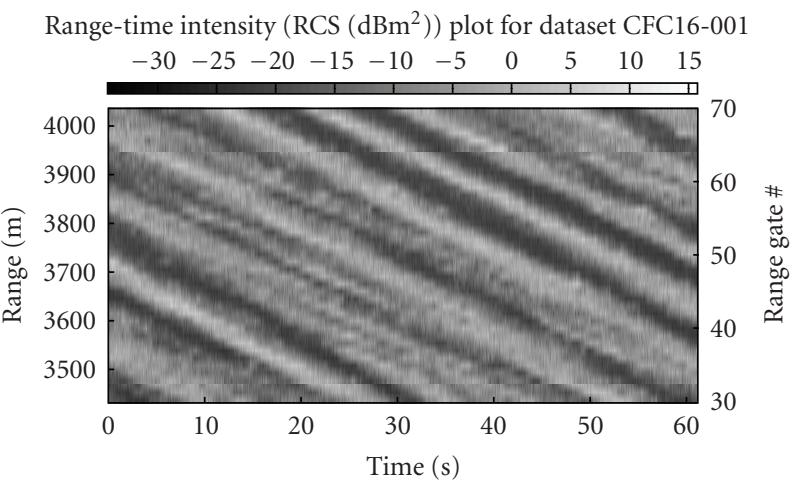

Figure 9: Range-time intensity plot for dataset CFC16-001.

TABLE 3: Empirical versus model amplitude statistics.

\begin{tabular}{lcccc}
\hline Sea state & Low & Low & High & High \\
\hline Grazing angle & $1^{\circ}$ & $0.5^{\circ}$ & $1^{\circ}$ & $0.5^{\circ}$ \\
$I_{2}$ & 3.57 & 2.27 & 6.05 & 4.61 \\
$I_{3}$ & 24.88 & 9.47 & 72.32 & 63.75 \\
$I_{4}$ & 261.9 & 66.88 & 1238.6 & 1629.6 \\
$\hat{\nu}$ & 1.18 & 2 & 0.57 & 1.22 \\
$\nu_{\text {model }}$ & 1.88 & 1.79 & 0.92 & 0.88 \\
\hline
\end{tabular}

sea state to local wind speed rather than $H_{s}$ in transient sea conditions (not fully developed).

The 2 nd to 4 th normalised intensity moments $I_{2}-I_{4}$ and the estimated shape parameter $\hat{v}$ are tabulated in Table 3, assuming a $k$-distributed envelope process and compared to the shape parameter model $\nu_{\text {model }}$ [15]. In this estimation, the theoretical relationship between the actual shape parameter $\hat{v}$ and the effective shape parameter $\hat{\nu}_{\text {eff }}$ in the presence of noise is used [18]:

$$
\hat{v}_{\text {eff }}=\hat{\nu}\left(1+\frac{1}{\mathrm{CNR}}\right)^{2} .
$$

The non-Rayleigh envelope statistics is evident. Theoretically spikiness should increase with a decrease in grazing angle. However, this is contradicted in the empirical analysis where a decrease in spikiness is observed with a decrease in grazing angle. This may be due to well-developed waves located closer to the radar $(3 \mathrm{~km})$ at the high grazing angles yielding increased spikiness, with less developed waves at the far-out ranges $(8 \mathrm{~km})$ where the low-grazing-angle sea clutter data was recorded.
These observations are indicative of the highly complex scattering environment and illustrate a still incomplete understanding of sea clutter.

\subsection{Average doppler characteristics}

As the capillary waves are the main scattering mechanisms at X-band and they are directly influenced by the nearsurface local wind [2], it can be expected that the Doppler and autocorrelation properties of sea clutter are directly influenced by the local wind. The sea clutter speckle autocorrelation $r(\tau)$ [14] is plotted in Figure 10 for four different datasets. From the magnitude response it is evident that the speckle decorrelation time is 10-20 milliseconds, which is consistent with literature [14]. It also indicates that the decorrelation time is affected by sea state, where the decorrelation time decreases as the sea state (roughness of the sea) increases. An explanation for this may be the more rapid deformation of the capillary waves in rough seas. The complex autocorrelation is strongly coupled to the Doppler characteristics of the sea clutter. Evaluation of the real and imaginary components of $r(\tau)$ reveals that the second zerocrossing of $\mathfrak{I}\{r(\tau)\}$ approximates $1 / 2$ of the mean projected Doppler period,

$$
f_{d}\left(\phi_{\text {wind }}\right) \approx\left[\left.2 \tau\right|_{(\tau>0, \Im\{r(\tau)\}=0)}\right]^{-1} .
$$

This together with the empirical model [3]

$$
f_{d}\left(\phi_{\text {wind }}\right) \approx \frac{2 v_{\text {wind }} \cos \left(\phi_{\text {wind }}\right) f_{0}}{4 c}
$$

enables the estimation of the local projected wind speed from an analysis of the estimated autocorrelation. With a complete azimuth scan of the radar it would be possible to infer both wind speed and direction. This lies outside the scope of this paper and will be the subject of future research.

\subsection{Spectrally inhomogeneous sea clutter}

Section 3.2 provided empirical evidence that the average wind speed can be inferred from the sea clutter speckle autocorrelation, which is strongly correlated to the average Doppler response thereof. Experimental data suggests however that the sea clutter spectrum is inhomogeneous in both range and time in general. High Doppler resolution spectrograms of three different geometrical configurations and environmental conditions are presented in Figures 1113. In addition to the spectrograms $I_{2}$ is plotted as a function 


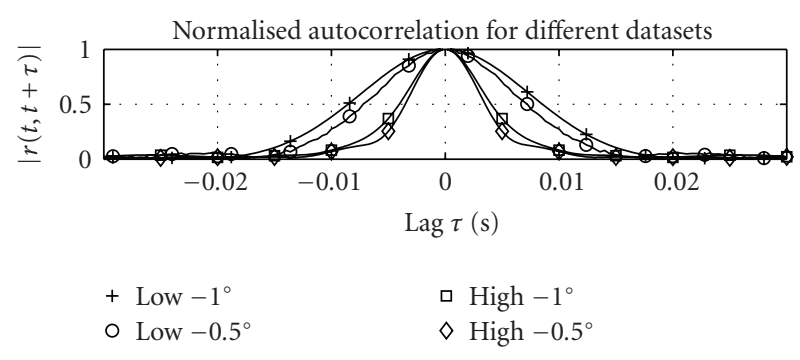

(a)

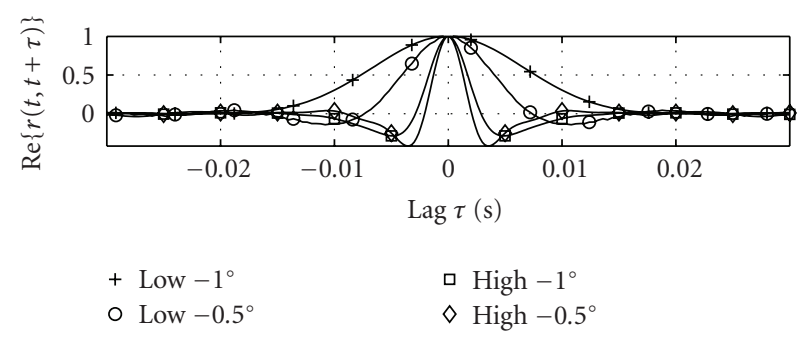

(b)

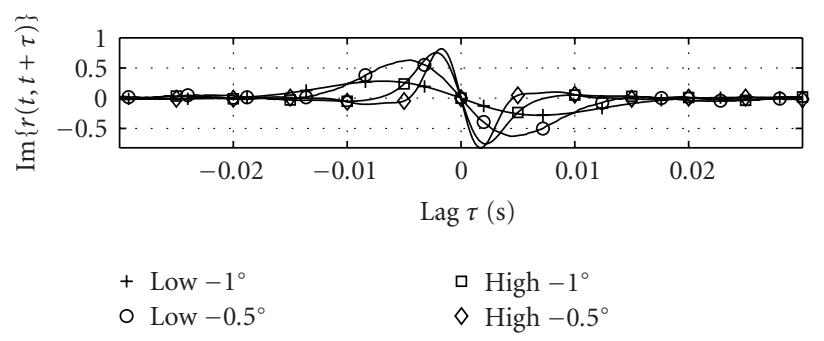

(c)

Figure 10: Speckle autocorrelation for different datasets: (a) magnitude, (b) real, and (c) imaginary.

of Doppler frequency, yielding an indication of the spikiness per Doppler resolution cell. The spectrogram in Figure 11 is representative of an up-swell sea $\left(H_{s}=3.4 \mathrm{~m}\right)$ with strongly developed waves and up-wind $\left(v_{\text {wind }}=15 \mathrm{kts}\right)$ configuration at a range of $3.8 \mathrm{~km}$. From the spectrogram the different individual waves can be distinguished as they are propagating through the given range cell. The different individual waves have very different Doppler spectra, which results in a significantly raised $I_{2}$ at the Doppler velocities associated with localised wind gusts. Thus in the Doppler domain these echoes will compete with those of real targets and hence may have an adverse effect on the false alarm rate. Since the individual waves are resolved, $I_{2}$ is also higher than 2 at the mean Doppler frequency. The spectrogram in Figure 12 is representative of a $70^{\circ}$ cross-swell sea $\left(H_{s}=\right.$ $2.8 \mathrm{~m})$ and down-wind $\left(v_{\text {wind }}=15 \mathrm{kts}\right)$ configuration at a range of $5.3 \mathrm{~km}$. The sea was more representative of open sea conditions. From the spectrogram it is clear that the shorttime Doppler spectrum is much more homogeneous and it is impossible to distinguish individual waves or events. At the mean Doppler frequency $I_{2}$ tends to the theoretical value of 2 and is only slightly raised at the average Doppler spectrum edges. The spectrogram in Figure 13 is representative of a $20^{\circ}$ up-swell sea $\left(H_{s}=2.5 \mathrm{~m}\right)$ and up-wind $\left(v_{\text {wind }}=7 \mathrm{kts}\right)$ configuration at a range of $5.6 \mathrm{~km}$. Once again the sea was representative of open sea conditions. For this dataset the short-time Doppler spectrum is inhomogeneous compared to the previous dataset, but not as severe as the first dataset analysed in this subsection. For this up-swell configuration there is evidence of individual waves propagating through the range cell, but it is clear that more than one wave are contained within the resolution cell. The events associated with the broadened Doppler response may be associated with whitecaps blown off the top of the waves by the higher wind and/or gusts. The spikiness at the Doppler frequencies associated with the local maximum wind speed is confirmed by a significant raise in $I_{2}$.

This brief analysis of the sea clutter Doppler spectrum and $I_{2}\left(f_{d}\right)$ suggests that it is possible to also infer the existence and severity of whitecaps from the sea clutter.

\subsection{Frequency agility}

It is generally accepted that sea clutter speckle decorrelates with frequency agility when the frequency step size exceeds the pulse bandwidth, $\Delta f_{c} \geq B$ [3]. The correlation coefficient $\rho\left(f_{0}, f_{n}\right)$ is plotted for a coherent processing interval (CPI) of 100 milliseconds at a fixed range cell over a period of 60 seconds-depicting the correlation between the base $\mathrm{Tx}$ frequency $f_{0}$ and an offset frequency of up to $f_{0}+130 \mathrm{MHz}$ for a pulse bandwidth of $10 \mathrm{MHz}$. From Figure 14 it can be concluded that in general the sea clutter speckle decorrelates whenever $\Delta f_{c} \geq B$. However, there are a number of CPIs where the speckle only decorrelates after a step size of $40 \mathrm{MHz}$. Discrete spike events can also be identified where there is strong correlation for a step size of up to $130 \mathrm{MHz}$. Most radar detection mechanisms will declare these spikes as targets. It is important to note that these discrete spike events have a typical lifetime of $0.5-2$ seconds.

Thus, overall these observations show broad agreement with those reported elsewhere and with the GIT and HYB models. They also re-emphasise the complexity of the scattering environment in which a target is required to be detected. This aspect is examined further in the following two sections.

\section{SMALL BOAT REFLECTIVITY ANALYSIS}

This section presents the results of the analysis of a range of small instrumented boats deployed during the two trials detailed in Section 2.

\subsection{Small boat $R C S$ and amplitude statistics}

The mean RCS of the small boats, averaged over aspect angle, have been estimated from the measured data and tabulated in Table 4. Isolation of the boat signature from the sea clutter was obtained by Doppler filtering, using the GPS-estimated Doppler frequency as input. The responses of the threerange cells closest to the GPS range were coherently added to counter range-gate straddling losses. The effects of multipath fading from smooth sea surfaces and of shadowing of the 

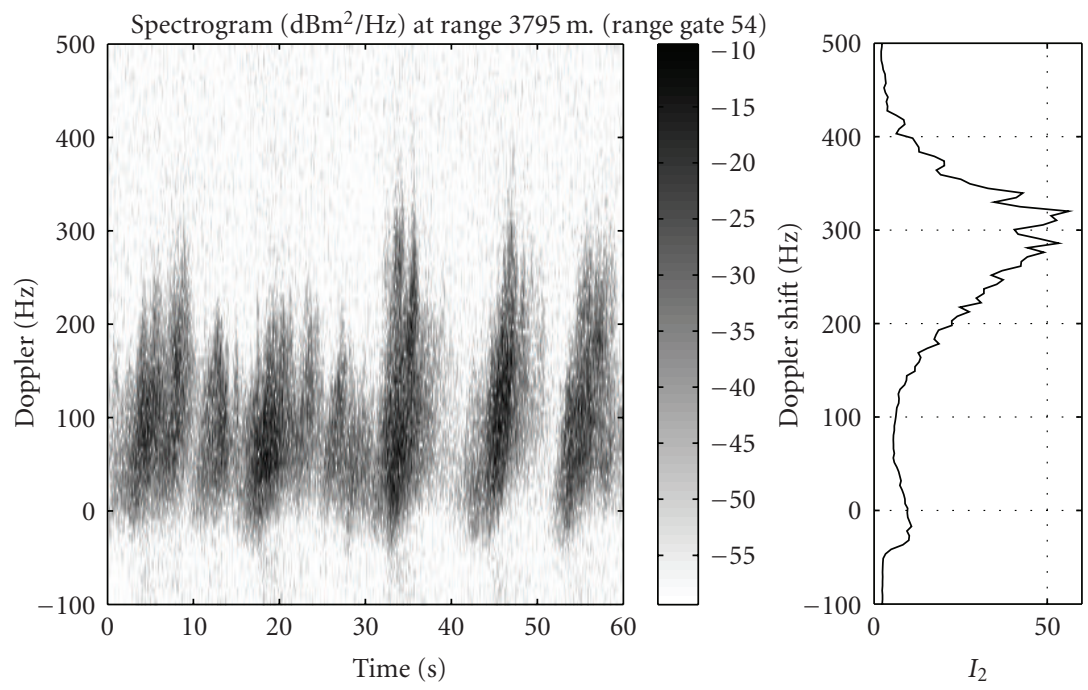

FIGURE 11: Spectrogram and $I_{2}$ for OTB dataset CFC16-001.
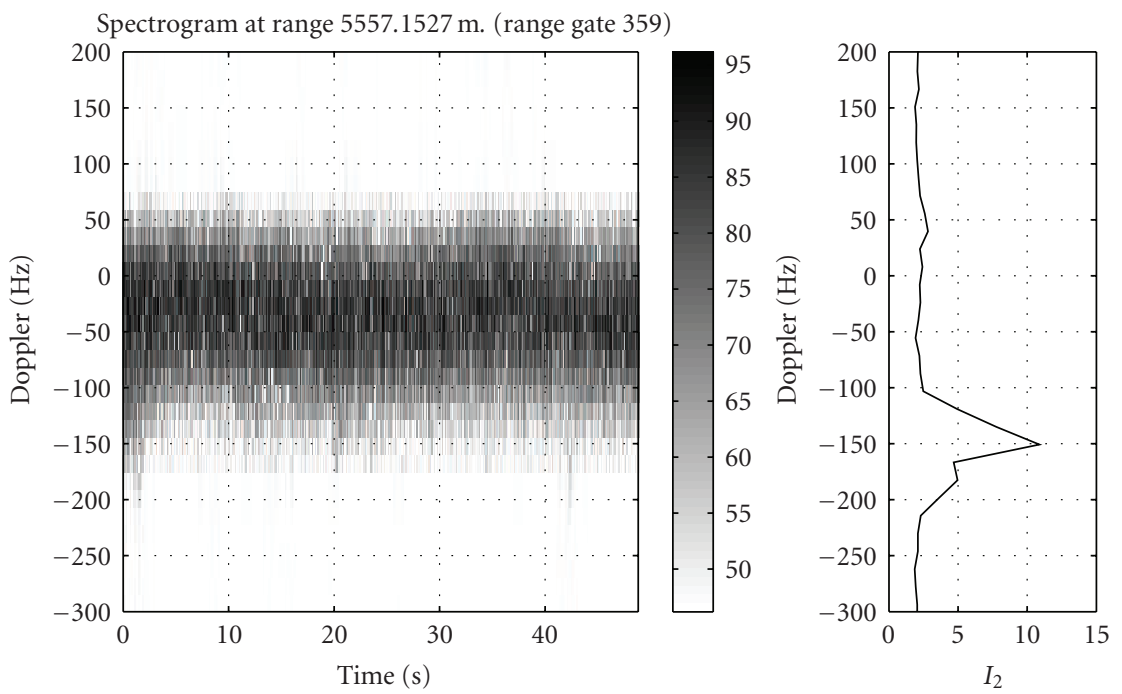

Figure 12: Spectrogram and $I_{2}$ for spectrally homogeneous Signal Hill dataset.
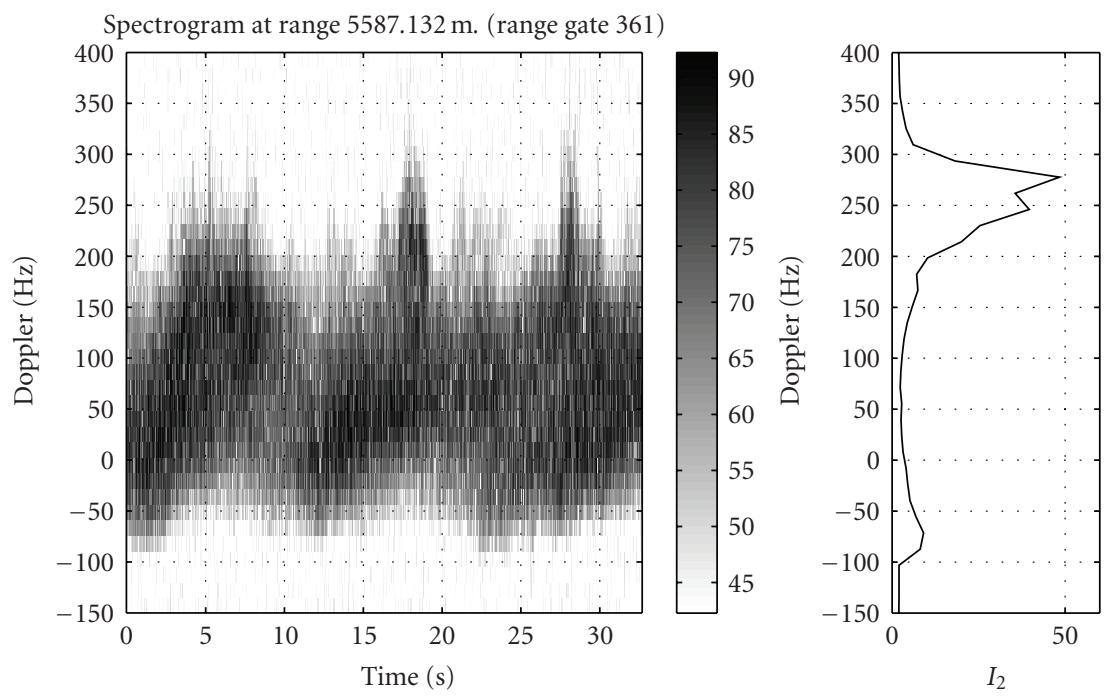

FIgURE 13: Spectrogram and $I_{2}$ for spectrally inhomogeneous Signal Hill dataset. 


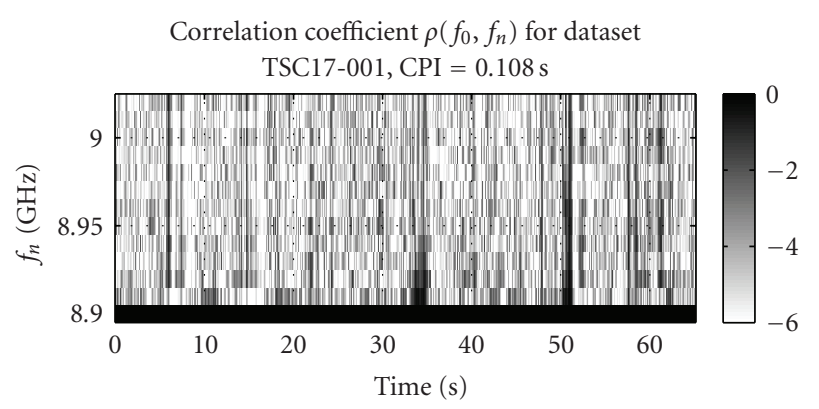

FIGURE 14: Sea clutter frequency agility decorrelation in the presence of discrete spikes.

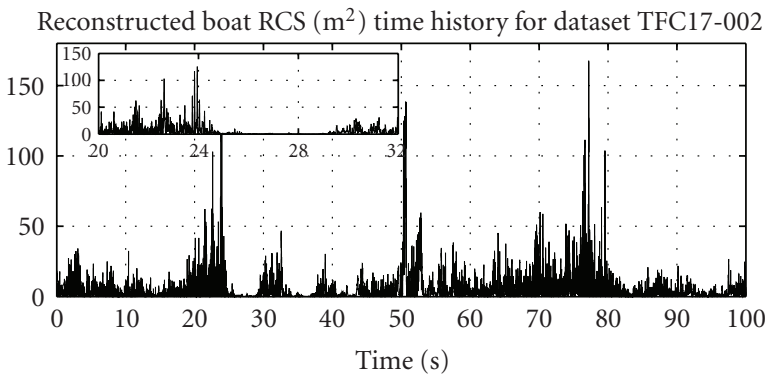

FIGURE 15: Reconstructed chokka fishing vessel RCS signature.

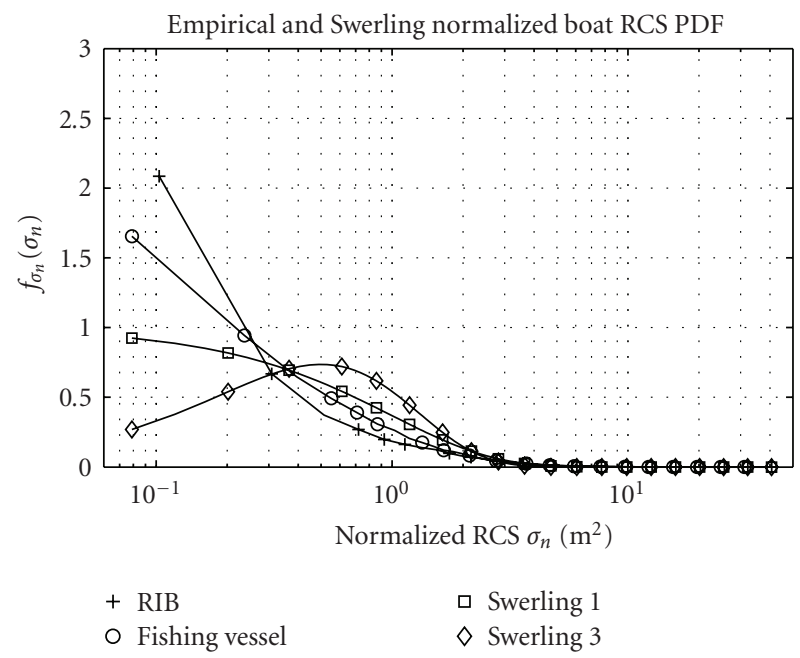

FIGURE 16: Empirical PDF of chokka fishing vessel and WaveRider RIB compared to Swerling models 1 and 3.

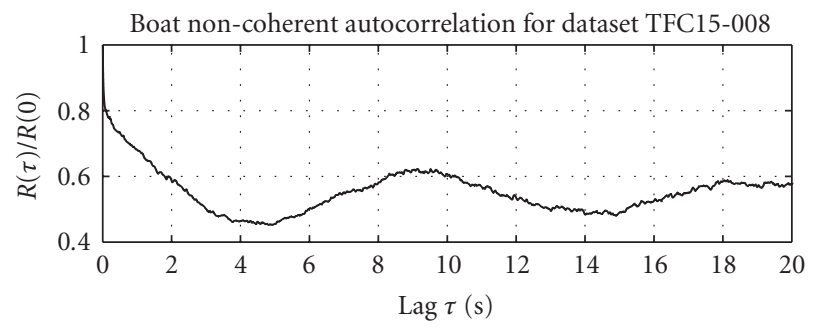

FIGURE 17: RIB non-coherent autocorrelation showing strong correlation with sea waves.
TABLe 4: Small boat RCS $\left[\mathrm{dBm}^{2}\right]$.

\begin{tabular}{lcccc}
\hline Boat description & Length & Width & Engines & RCS $\left(\mathrm{m}^{2}\right)$ \\
\hline Pencilduck & $4.2 \mathrm{~m}$ & $1.6 \mathrm{~m}$ & $1 \times 50 \mathrm{hp}$ & $\approx 1$ \\
SANParks RIB & $4.8 \mathrm{~m}$ & $1.8 \mathrm{~m}$ & $1 \times 60 \mathrm{hp}$ & $1-3$ \\
WaveRider RIB & $6.5 \mathrm{~m}$ & $2 \mathrm{~m}$ & $2 \times 85 \mathrm{hp}$ & $1-5$ \\
Ski Boat & $5.2 \mathrm{~m}$ & $1.8 \mathrm{~m}$ & $2 \times 85 \mathrm{hp}$ & $4-15$ \\
Chokka Fishing Vessel $6.2 \mathrm{~m}$ & $2 \mathrm{~m}$ & $1 \times$ inboard & $5-16$ \\
\hline
\end{tabular}

boat in higher sea states on the RCS values were not corrected for in the results presented in Table 4.

From Table 4 it is clear that the RCS of an RIB is related to its physical size and ranges between $1-5 \mathrm{~m}^{2}$. The RCS of solid boats are larger in general, with the mean RCS of the chokka fishing vessel up to $16 \mathrm{~m}^{2}$. In addition to the mean RCS of the small boat it is also critical for detection performance calculation to have a good model for its RCS fluctuation. The isolated boat RCS signature for the chokka fishing vessel is plotted in Figure 15, with the empirical probability density function (PDF) plotted for both the chokka fishing vessel and the WaveRider RIB in Figure 16.

Slight differences between the PDFs of the two boats are visible as well as the inability of the Swerling models to accurately describe their amplitude distributions. A characteristic of small boats in heavy sea is the fading of the RCS as the boat steers into the troughs of the waves, as indicated by the close-up view about 25-29 seconds in Figure 15. This suggests a strong correlation of boat RCS with the local sea waves and explains the poor fit of the empirical PDFs to the Swerling models at low RCS values. The noncoherent autocorrelation of a boat steering directly into the waves (Figure 17) shows periodicity with the same period as the mean sea wave period. This correlation of boat RCS and sea clutter echo strength further complicates an already challenging detection problem.

\subsection{Small boat doppler bandwidth}

The Doppler bandwidth of a target is an important design parameter for optimal coherent detection. Coherent processing gain is only achieved by an increase in the CPI whilst it still remains less than or equal to the inverse of the target Doppler bandwidth. High Doppler resolution spectrograms have been computed for the different small boats, with the results for CPI's of 10 milliseconds and 200 milliseconds plotted in Figure 18 for the WaveRider RIB.

The Doppler bandwidth for the WaveRider RIB can be observed from the high-resolution spectrogram. As for most of the other small boats, this is approximately $10 \mathrm{~Hz}$. This yields an optimal CPI ranging between 100-200 milliseconds. As the CPI increases beyond this value, the boat energy will start to spread over multiple Doppler resolution cells, yielding no additional coherent processing gain. This is a key consideration in the design of an optimal detector. 


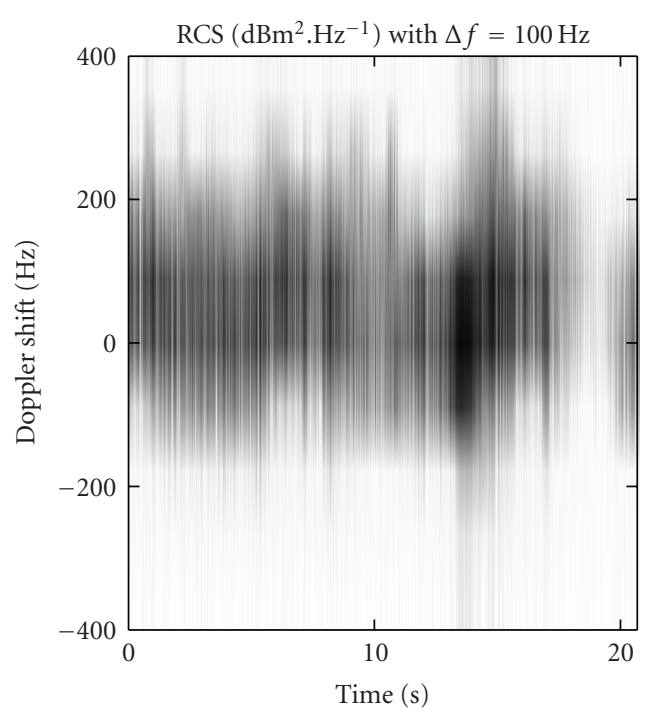

(a)
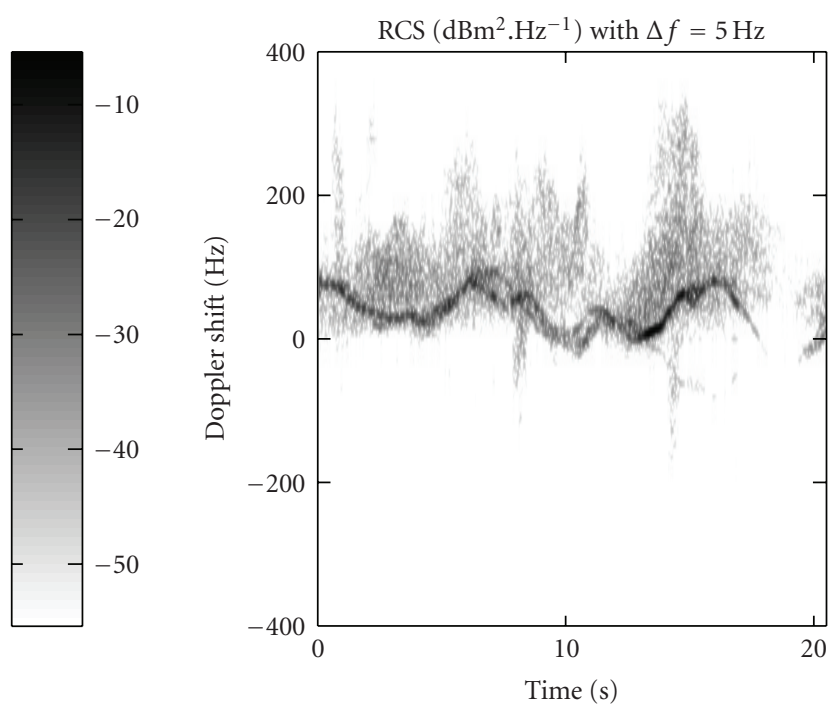

(b)

FIGURE 18: High Doppler resolution spectrograms for different CPI's: (a) 10 milliseconds, and (b) 200 milliseconds.

\subsection{Highly manoeuverable small boats}

Due to its small size, light weight and powerful engines, the RIB class of small boats is highly manoeuvrable with the ability to reach speeds of up to $40 \mathrm{kts}$ for even the small $4.2 \mathrm{~m}$ pencilduck. Especially in the design of coherent detection and tracking algorithms, it is important to have a good understanding of the anticipated manoeuvrability of the target. In addition, the disturbance of the manoeuvring boat on the local sea surface may also greatly influence its detectability either adversely or positively. The high Doppler resolution spectrograms of two different RIB's are plotted in Figure 19-21 for three different manoeuvres. The narrow Doppler response of the drifting pencilduck (Figure 19) is evident, as well as the slight movement of the pencilduck due to the local waves. The drifting pencilduck caused little disturbance on the local sea surface. The WaveRider RIB steering radially outbound at a speed of about 10 kts (Figure 20) had a narrow Doppler response, with a local disturbance of the sea surface visible when the RIB was crashing through the crests of the waves. This local disturbance is observed as quite broad Doppler bandwidth noise with Doppler velocities ranging from slightly higher than the speed of the boat down to the Doppler velocity of the local sea clutter speckle. The spectral density of the disturbance is $20 \mathrm{~dB}$ lower than the boat signature. The pencilduck racing at $40 \mathrm{kts}$ radially outbound (Figure 21) still had a narrow Doppler response for the body of the boat, but caused a significant local disturbance of the sea water (e.g., splashing waves and water spray by the propeller), decreasing the localised signal-to-interference ratio (SIR) to less than $-10 \mathrm{~dB}$. With such a low SIR, it becomes increasingly difficult to detect the boat with clutter suppression algorithms, even though the local disturbance of the sea surface may be detected by a basic envelope thresholding detector. However, there is still ample Doppler separation between the boat and interference, and in principal a long dwell time range-Doppler detector could be constructed that will consistently declare detections for this fast moving boat. Also of interest is the case where the boat is racing crossrange. This still yields strong self-induced interference, but the Doppler response of the body of the boat will be buried within the interference and it will become extremely difficult to detect.

From this subsection it can be concluded that the exact manoeuvre of the small boat has a great influence on its detectability, especially due to its potential disturbance to the local sea surface. It is also clear that not only the speed, but also the heading of small boats has to be modelled for accurate performance prediction.

\subsection{Frequency agility correlation for small boats}

Theoretically the correlation coefficient $\rho\left(f_{0}, f_{n}\right)$ for the RCS of a point scatterer for different frequencies should be unity. For a target that can be approximated as a point scatterer it is assumed that $\left|\rho\left(f_{0}, f_{n}\right)\right| \rightarrow 1$. In the presence of clutter and multipath fading, the correlation will be adversely effected. $\rho\left(f_{0}, f_{n}\right)$ is plotted in Figure 22 for a CPI of 100 milliseconds for the two range cells containing most of the energy for the chokka fishing vessel.

The frequency agility correlation for the boat exceeded 0.5 with $\Delta f_{c}=100 \mathrm{MHz}$ for $84 \%$ of the total time period, compared to only $10 \%$ for sea clutter only as represented in Figure 14. There were time periods when the correlation coefficient dropped to similar levels as the sea clutter, which coincided with low levels of SCR and/or SNR. For a $10 \mathrm{MHz}$ pulse bandwidth empirical evidence suggest that small boats exhibit significant frequency agility correlation for frequency step sizes up to and beyond $130 \mathrm{MHz}$. It is possible to design a detection algorithm that uses $\rho\left(f_{0}, f_{n}\right)$ as the basis for its 


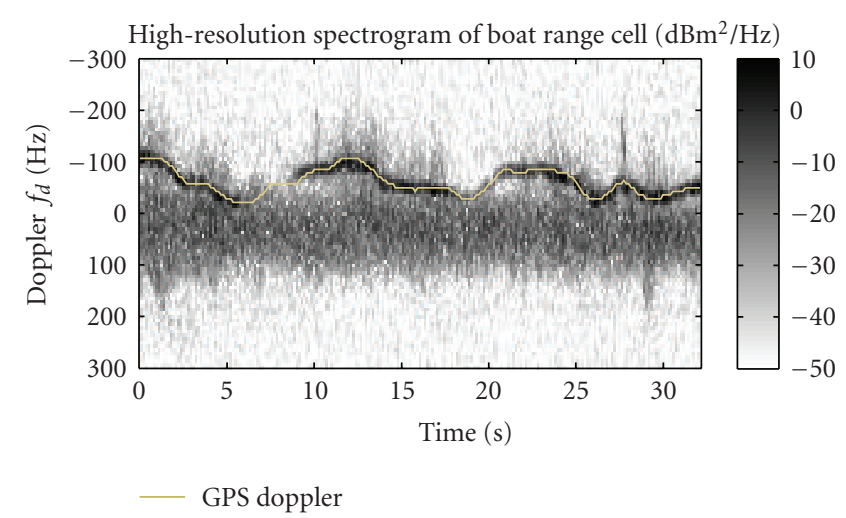

FIgURE 19: High Doppler resolution spectrogram for drifting pencilduck.

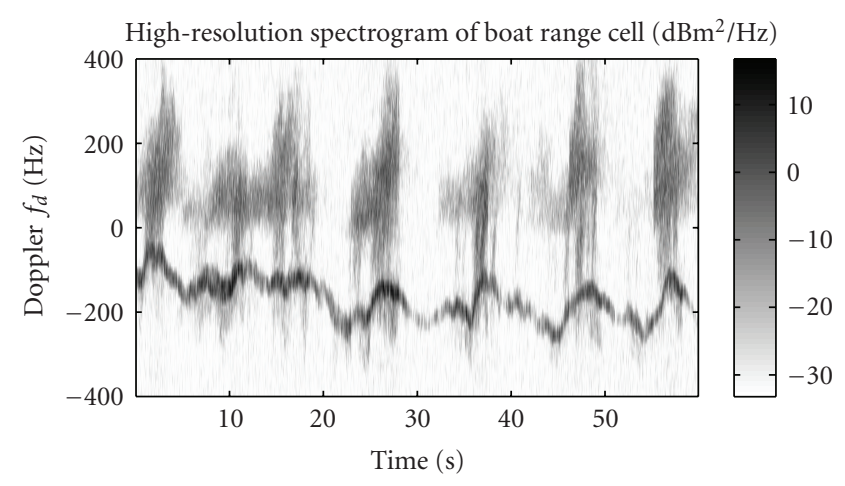

FIgURE 20: High Doppler resolution spectrogram for radial outbound WaveRider RIB.

test statistics. This detector may still detect discrete spikes, since they have similar characteristics as the small boats (e.g., at $t \in(6,51) s$ in Figure 14). Once again, these discrete spikes only have a limited lifetime of less than 2 seconds.

\section{DETECTABILITY OF SMALL BOATS}

This section presents the detectability of small boats undergoing different manoeuvres using the ALQ detector as an example of the asymptotically optimal class of detectors.

\subsection{Overview of the ALQ detector}

The ALQ detector is designed by extending the generalized likelihood ratio test approach, as suggested by Kelly [9] for Gaussian interference, to the spherically invariant random process model for non-Gaussian interference [19]. Assume that the radar transmits a coherent train of $m$ pulses. The associated $m$ received complex samples can be constructed as a vector $\mathbf{z}=[z(1), \ldots, z(m)]^{T}$. Under the assumption that $\mathbf{M}$ is known exactly, the ALQ detector can be expressed mathematically as

$$
\frac{\left|\mathbf{p}^{H} \mathbf{M}^{-1} \mathbf{z}\right|^{2}}{\left(\mathbf{p}^{H} \mathbf{M}^{-1} \mathbf{p}\right)\left(\mathbf{z}^{H} \mathbf{M}^{-1} \mathbf{z}\right)} \stackrel{{ }_{H 0}}{\gtrless} \chi_{t},
$$

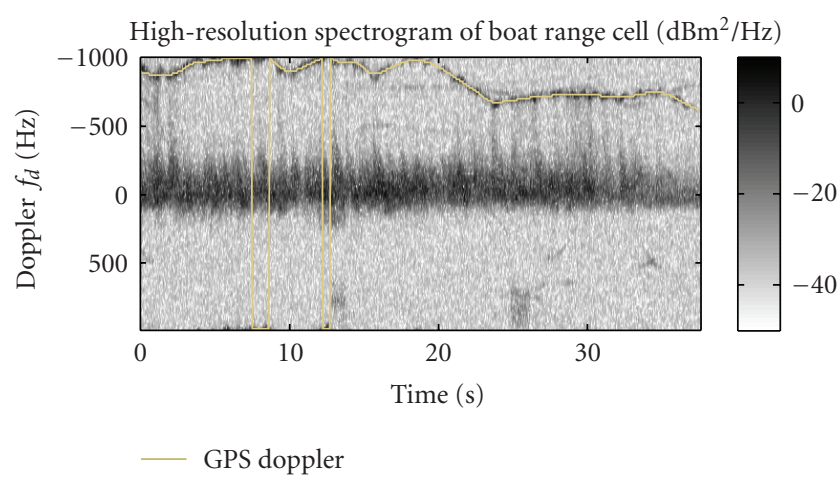

FIGURE 21: High Doppler resolution spectrogram for pencilduck racing at $40 \mathrm{kts}$ radially outbound.

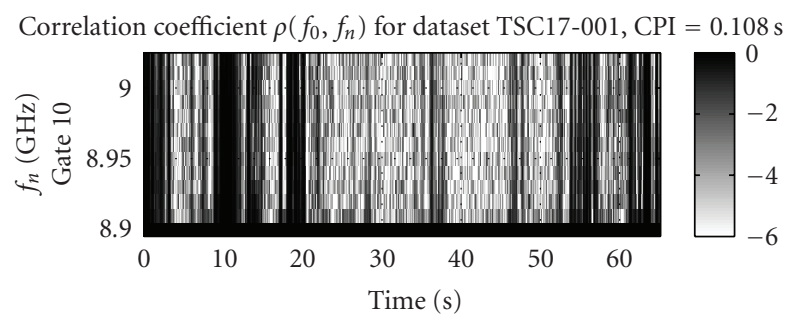

(a)

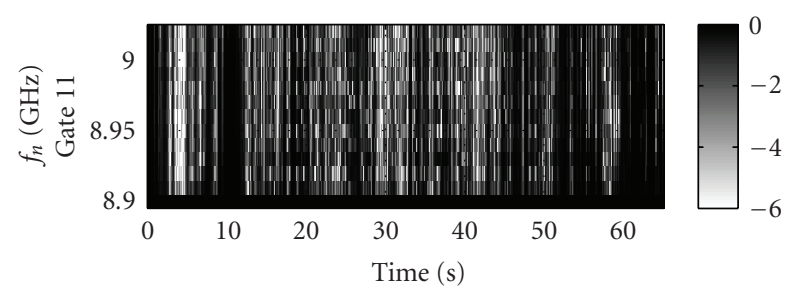

(b)

FIGURE 22: Frequency agility correlation for chokka fishing vessel: (a) gate 10, and (b) gate 11.

where $\mathbf{p}$ is the steering vector typically constructed with elements $p_{i}=e^{j 2 \pi i f_{d} T}[20], T$ the radar PRI and $f_{d}$ the target Doppler frequency [11]. It is generally accepted that $\mathbf{M}$ is highly dependent on the radar configuration, geometry, and the environmental conditions and has to be estimated from adjacent range gates that are not contaminated by the boat itself. Various estimation techniques have been proposed [21]. Gini and Greco [11] describe one such technique that makes a good compromise between detection losses and hardware processing requirements:

$$
\widehat{\mathbf{M}}_{\mathrm{AML}}(i+1)=\frac{1}{K} \sum_{k=1}^{K} \frac{m \cdot \mathbf{z}_{k} \mathbf{z}_{k}^{H}}{\mathbf{M}_{\mathrm{AML}}(i)^{-1} \mathbf{z}_{k}},
$$

for $i=0,1,2, \ldots, N_{\mathrm{it}}$. During each iteration the approximately maximum likelihood (AML) estimation is normalized such that its trace is equal to $\mathrm{m}$. Since the ALQ detector involves inversion of $\mathbf{M}$, care has to be taken to ensure that the matrix does not become singular. This can be ensured by setting the number of independent sea clutter time vectors 


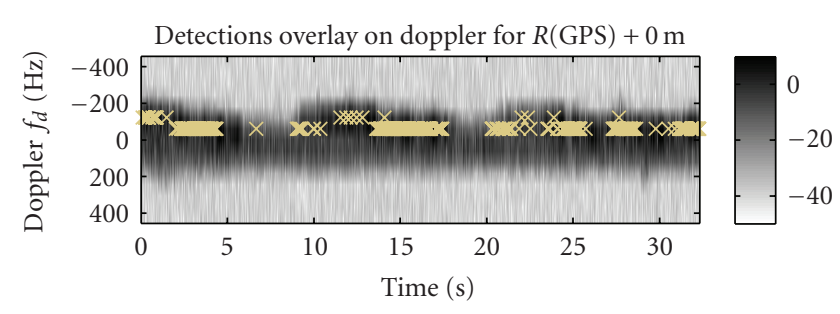

$\times$ ALQ detection

(a)

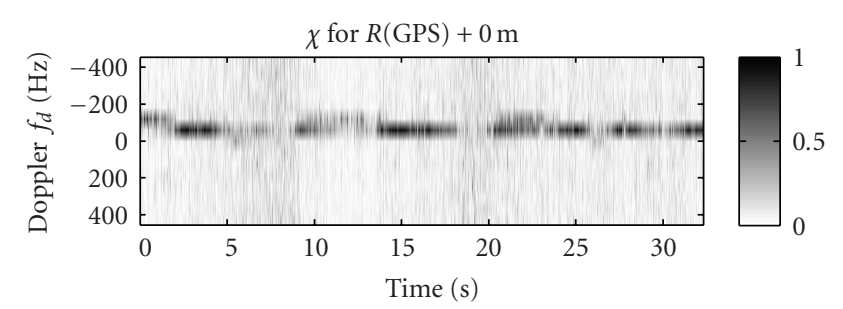

(b)

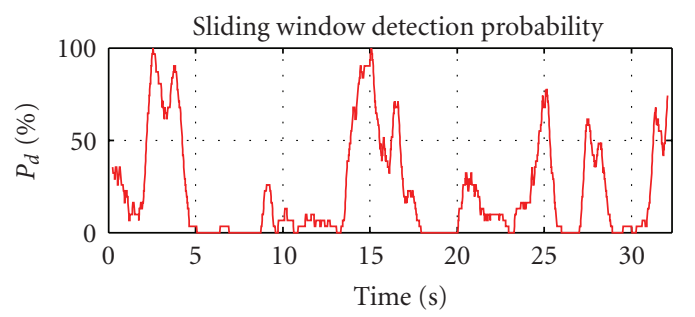

(c)

FIGURE 23: ALQ performance for drifting pencilduck: (a) spectrogram with detections, (b) test statistic $\chi$, and (c) sliding window $P_{d}$.

at different range gates $k$ equal to at least the length of the test vector $m, k \geq m$ [9]. Detectability can be improved by increasing this ratio, but at the expense of increased hardware processing requirements.

\subsection{ALQ performance for different RIB manoeuvres}

In the first dataset evaluated, the $4.2 \mathrm{~m}$ pencilduck was floating close the southwestern shore of Robben Island, with $H_{s}=3 \mathrm{~m}$ and $v_{\text {wind }}=6 \mathrm{kts} \mathrm{NE}$. The radar look angle was $343^{\circ} \mathrm{N}$ at range $R=11 \mathrm{~km}$ with grazing angle $\theta=1.5^{\circ}$. SCR and CNR were $6 \mathrm{~dB}$ and $24 \mathrm{~dB}$, respectively. Figure 23(a) plots the spectrogram with a dwell time equal to that of the ALQ detector with the Doppler-dependent thresholding detections overlaid for $P_{\mathrm{FA}}=10^{-4}$. Figure 23(b) plots the test statistic $\chi$. Figure 23(c) plots the sliding window $P_{d}$ with window length $L=31$, with $E\left\{P_{d}\right\}=23 \%$. For such a low SIR this is rather significant. The ability of the detector to whiten the sea clutter is clear in Figure 23(b), whilst the boat signature shows very little evidence of decorrelation. The fading in target signature and the subsequent fading in detectability may very well be due to shadowing of the boat by the sea waves.

In the second dataset, the WaveRider RIB was steering away from the radar into the well-developed waves at a speed

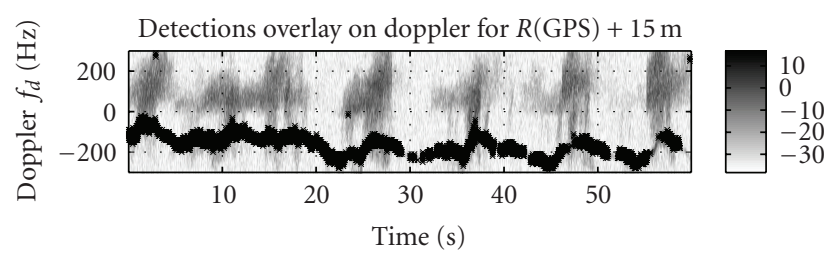

$\times$ Detections

(a)

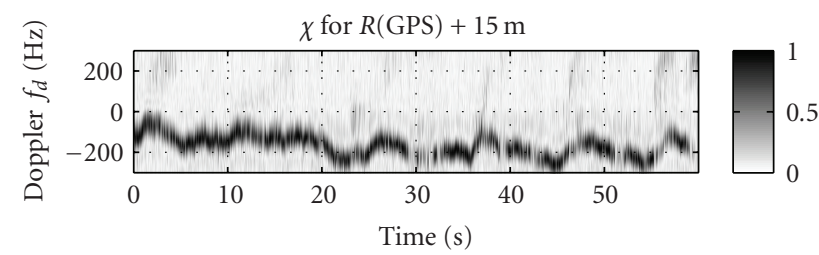

(b)

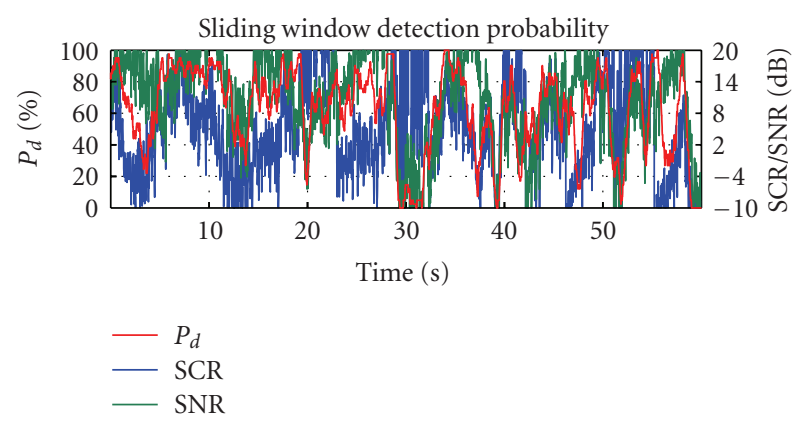

(c)

FIGURE 24: ALQ performance for $10 \mathrm{kts}$ WaveRider RIB: (a) spectrogram with detections, (b) test statistic $\chi$, and (c) sliding window $P_{d}$.

of $10 \mathrm{kts}$ at range $R=3.3 \mathrm{~km}$. The radar look angle was $166^{\circ} \mathrm{N}$, whilst $H_{s}=3.2 \mathrm{~m}$ and $v_{\text {wind }}=16 \mathrm{kts}$ SSE. SCR and CNR were $4 \mathrm{~dB}$ and $17 \mathrm{~dB}$, respectively. The performance of the ALQ detector for $P_{\mathrm{FA}}=10^{-4}$ is plotted in Figure 24, with $E\left\{P_{d}\right\}=62 \%$. Even though the SCR is lower than in the previous case, a significant increase in $P_{d}$ is observed. This is most probably due to the increased Doppler separation. Figure 24(c) indicates that low $P_{d}$ is in general associated with low SCR and/or low SNR.

With the observed increase in sensitivity with an increase in Doppler separation, it can be expected that detectability will increase even further for the high-speed pencilduck. The performance of the ALQ detector is plotted in Figure 25 for the pencilduck racing at $40 \mathrm{kts}$ radially outbound at a range of $21.5 \mathrm{~km}$. Even though the boat can be distinguished in the high Doppler resolution spectrogram (Figure 21) the ALQ detector only manages very intermittent detections. The sea clutter and localised disturbance are whitened over all Doppler, effectively masking the boat. In this case the ALQ cannot be classified as an asymptotically optimal, since a range-Doppler cell-averaging CFAR detector can be configured to steadily detect the boat due to the separation in Doppler of the interference and the boat signature and its narrow Doppler spectrum. 


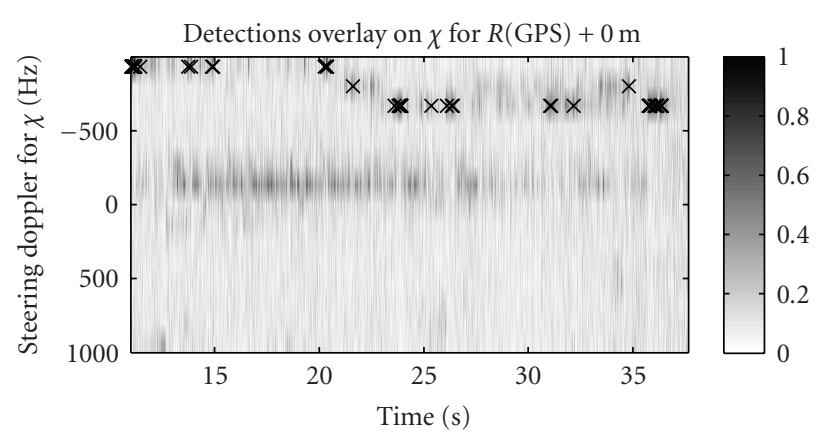

$\times$ ALQ detection

FIGURE 25: ALQ masking of fast moving pencilduck.

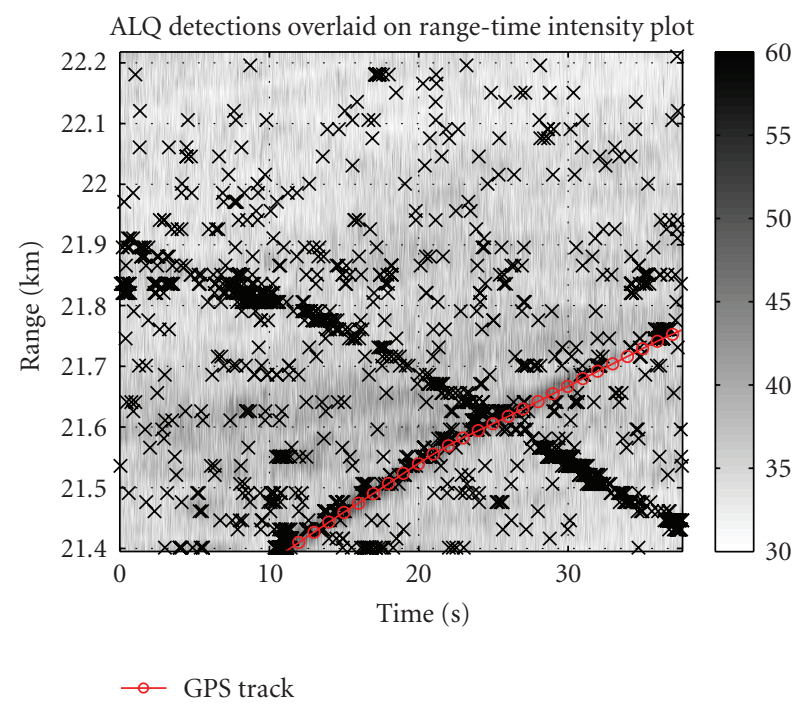

FIGURE 26: Detection of seagulls and an angel with the ALQ detector.

\subsection{Detection of seagulls and angels}

With improved subclutter visibility, the problem arises that first detections are declared not only for small boats, but also for large birds such as seagulls. ALQ detections for the last dataset in Section 5.2 are overlaid on the rangetime intensity plot in Figure 26. Even though only intermittent detections were declared for the racing pencilduck, a large number of detections were declared for the entire dataset. Examination of these detections reveals that they coincide with scatterers yielding an RCS of approximately $0.01-0.1 \mathrm{~m}^{2}$ and a narrow Doppler spectrum with very fast acceleration. Comparing this to the Doppler signatures of birds in [13] and observation by the copilot of the pencilduck led to the conclusion that these scatterers are indeed seagulls.

Of particular interest in Figure 26 is the consistent detections declared from a range of $21.9 \mathrm{~km}$ at $t=0$ second closing in to a range of $21.4 \mathrm{~km}$. Closer inspection revealed that this was a flock of about 6 seagulls flying in formation. The combined RCS of this "angel" was $10 \mathrm{~dB}$ lower than the pencilduck, but still yielded significantly higher $P_{d}$. The main reason for this is the Doppler separation and that the seagulls caused no local disturbance of the sea surface. The resultant SIR for the angel was indeed higher than for the pencilduck. As radar sensitivity is increased, this will become a more and more significant problem.

\section{CONCLUSIONS}

Current commercial products provide near real-time estimation of basic wave and surface current parameters using the video output of standard X-band marine radar. This paper investigated sea clutter and small boat reflectivity in the littoral and proved that sea clutter reflectivity is related to $v_{\text {wind }}$ rather than $H_{s}$. Temporal characteristics of sea clutter were investigated, with empirical results suggesting that $v_{\text {wind }}$ and $\phi_{\text {wind }}$ can be estimated from the sea clutter speckle autocorrelation. The spectral inhomogeneity of sea clutter was investigated for different sea conditions. The brief analysis of the sea clutter Doppler spectrum and $I_{2}\left(f_{d}\right)$ suggested that it is possible to also infer the existence and severity of whitecaps from the sea clutter. Discrete spikes in sea clutter were clearly visible when the frequency agility decorrelation was estimated.

For safe navigation, it is pertinent that the detection capabilities of marine radar in adverse conditions are improved, especially for small boats. This requires an in-depth understanding of the dynamics and associated reflectivity of these boats. The absolute RCS, amplitude statistics, and temporal characteristics of a range of small boats have been analysed using a comprehensive set of recorded datasets. Of particular interest were the dependency of the boat reflectivity on the local sea, deviation from the Swerling RCS models, the perceived persistence of reflectivity for short periods of time and the distinguishable pulse-to-pulse frequency agility correlation properties of small boats. It was shown using real data that the ALQ detector can, under certain conditions, be subject to selfmasking. A definite contribution to the knowledgebase is the importance of not only modelling the sea clutter and boat reflectivity accurately, but also to model the local disturbance caused by small boats, especially during fast manoeuvring.

\section{ACKNOWLEDGMENTS}

The authors acknowledge the CSIR team for their contribution in the planning and execution of the trial; the South African Department of Defence, the South African National Parks Board, the National Sea Rescue Institute, and the South African Weather Services for their contribution to the execution and funding of the measurement trials; as well as the Armaments Corporation of South Africa and the South African Air Force for permission to use the Fynmeet radar. The research was cofunded by the South African Department of Science and Technology, the South African Department of Defence and the Royal Society. 


\section{REFERENCES}

[1] K. Reichert, K. Hessner, and B. Lund, "Coastal applications of X-band radar to achieve spatial and temporal surface wave monitoring," in Proceedings of the OCEANS Europe Conference, K. Hessner, Ed., pp. 1-6, Aberdeen, Scotland, June 2007.

[2] J. N. Briggs, Target Detection by Marine Radar, vol. 16 of IEE Radar, Sonar and Navigation Series, The Institution of Electrical Engineers, London, UK, 2004.

[3] F. E. Nathanson, Radar Design Principles: Signal Processing and the Environment, SciTech, Mendham, NJ, USA, 1999.

[4] J. P. Reilly and G. D. Dockery, "Influence of evaporation ducts on radar sea return," IEE Proceedings Part F, vol. 137, no. 2, pp. 80-88, 1990.

[5] K. D. Ward, R. J. A. Tough, and S. Watts, Sea Clutter: Scattering, the K Distribution and Radar Performance, vol. 20 of IET Radar, Sonar and Navigation Series, IET, London, UK, 2006.

[6] P. L. Herselman and C. J. Baker, "Analysis of calibrated sea clutter and boat reflectivity data at C-and X-band in South African coastal waters," in The IET International Conference on Radar Systems (RADAR '07), p. 5, Edinburgh, UK, October 2007.

[7] "Report on the investigation of the loss of the sailing yacht ouzo and her three crew south of the isle of wight during the night of 20/21 august 2006," Investigation Report 7/2007, Marine Accident Investigation Branch, Southampton, UK, April 2007.

[8] B. Wade, "Sharpeye: a new technology marine radar," in The IET International Conference on Radar Systems (RADAR '07), Edinburgh, UK, October 2007.

[9] E. J. Kelly, "An adaptive detection algorithm," IEEE Transactions on Aerospace and Electronic Systems, vol. 22, no. 2, pp. 115-127, 1986.

[10] F. Gini, M. V. Greco, K. J. Sangston, and A. Farina, "Coherent adaptive radar detection in non-Gaussian clutter," in Proceedings of the 31st Asilomar Conference on Signals, Systems of Computers, vol. 1, pp. 255-259, Pacific Grove, Calif, USA, November 1997.

[11] F. Gini and M. Greco, "Covariance matrix estimation for CFAR detection in correlated heavy tailed clutter," Signal Processing, vol. 82, no. 12, pp. 1847-1859, 2002.

[12] M. McDonald and S. Lycett, "Fast versus slow scan radar operation for coherent small target detection in sea clutter," IEE Proceedings: Radar, Sonar and Navigation, vol. 152, no. 6, pp. 429-435, 2005.

[13] W. L. Flock and J. L. Green, "The detection and identification of birds in flight, using coherent and noncoherent radars," Proceedings of the IEEE, vol. 62, no. 6, pp. 745-753, 1974.

[14] A. Farina, F. Gini, M. V. Greco, and L. Verrazzani, "High resolution sea clutter data: statistical analysis of recorded live data," IEE Proceedings: Radar, Sonar and Navigation, vol. 144, no. 3, pp. 121-130, 1997.

[15] K. D. Ward, C. J. Baker, and S. Watts, "Maritime surveillance radar-part 1: radar scattering from the ocean surface," IEE Proceedings Part F, vol. 137, no. 2, pp. 51-62, 1990.

[16] F. Anderson, "Awarenet: persistent, ubiquitous surveillance technologies for enhanced national security," Brochure, CSIR, Pretoria, South Africa, October 2007, http://www.csir.co.za/dpss/brochures.html.

[17] R. Hamann, "Wind climatology of the south western cape," January 2006, http://www.windsurfingafrica.org/Articles/ tabid/285/Default.aspx.
[18] S. Watts, "Radar detection prediction in K-distributed sea clutter and thermal noise," IEEE Transactions on Aerospace and Electronic Systems, vol. 23, no. 1, pp. 40-45, 1987.

[19] E. Conte and M. Longo, "Characterisation of radar clutter as a spherically invariant random process," IEE Proceedings Part F, vol. 134, no. 2, pp. 191-197, 1987.

[20] F. Gini, "Sub-optimum coherent radar detection in a mixture of K-distributed and Gaussian clutter," IEE Proceedings: Radar, Sonar and Navigation, vol. 144, no. 1, pp. 39-48, 1997.

[21] F. Gini, "Performance analysis of two structured covariance matrix estimators in compound-Gaussian clutter," Signal Processing, vol. 80, no. 2, pp. 365-371, 2000. 

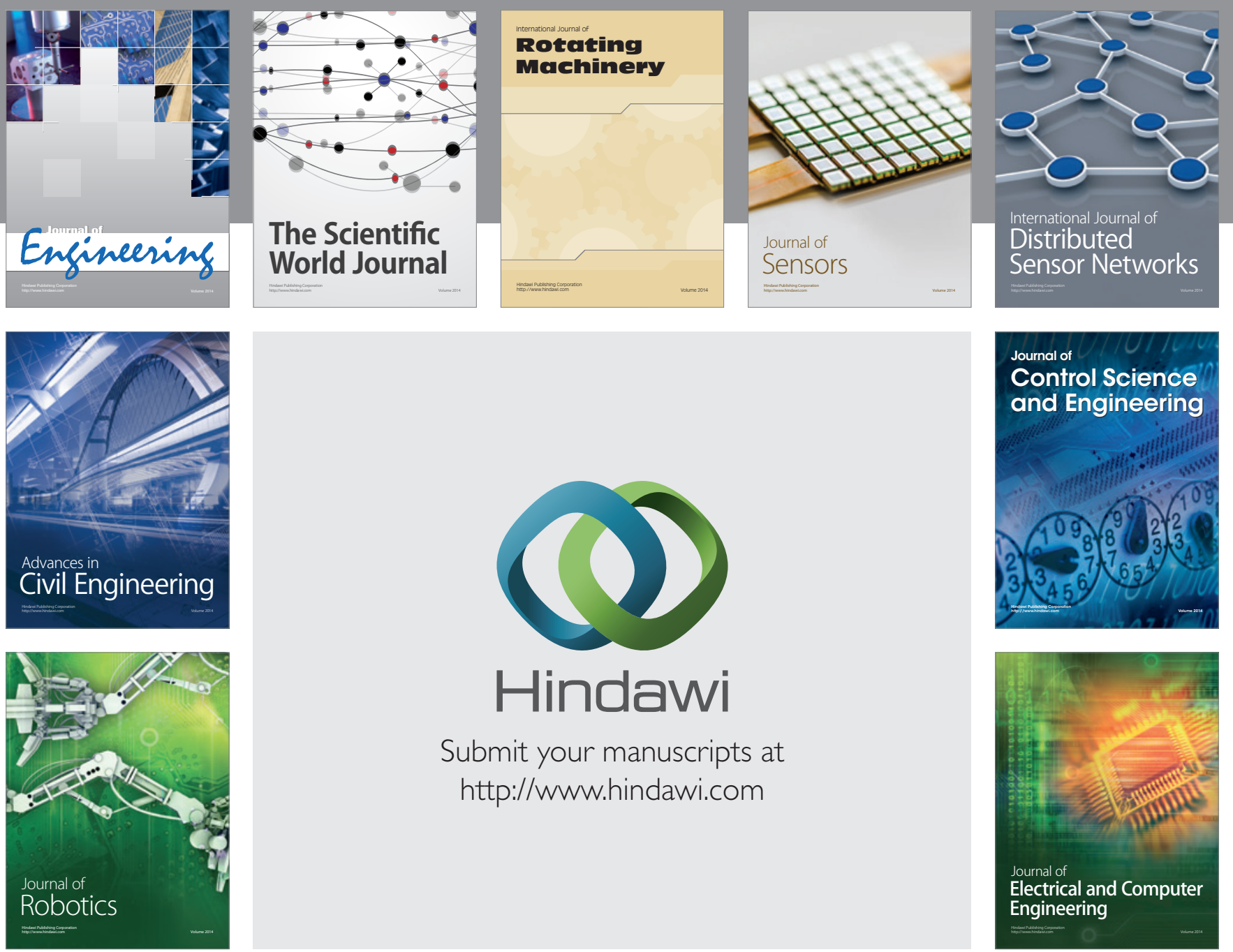

Submit your manuscripts at

http://www.hindawi.com
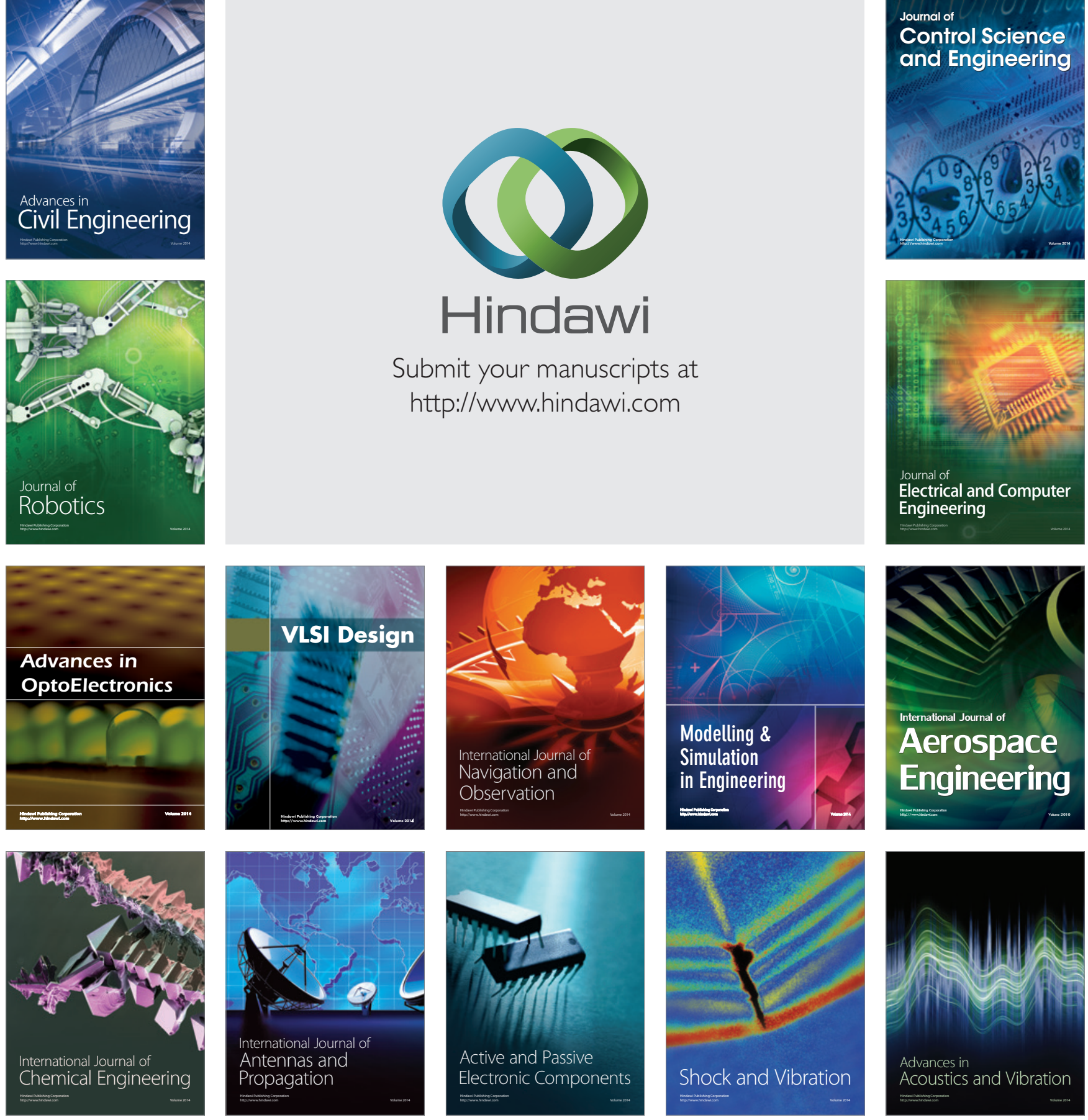